\section{Summary and agreement statement of the first International Conference on Concussion in Sport, Vienna $2001^{*}$}

\author{
M Aubry, R Cantu, J Dvorak, T Graf-Baumann, \\ K Johnston (Chair), J Kelly, M Lovell, P McCrory, \\ W Meeuwisse, P Schamasch (the Concussion in Sport \\ (CIS) Group)
} Recommendations for the improvement of safety and health of
athletes who may suffer concussive injuries

n November 2001, the first International Symposium on Concussion in Sport was held in Vienna, Austria. This symposium was organised by the International Ice Hockey Federation (IIHF), the Federation Internationale de Football Association Medical Assessment and Research Centre (FIFA, F-MARC), and the International Olympic Committee Medical Commission (IOC).

The aim of the symposium was to provide recommendations for the improvement of safety and health of athletes who suffer concussive injuries in ice hockey, football (soccer), and other sports. To this end a range of experts were invited to address specific issues of epidemiology, basic and clinical science, grading systems, cognitive assessment, new research methods, protective equipment, management, prevention, and long term outcome, and to discuss a unitary model for understanding concussive injury. At the conclusion of the conference, a small group of experts were given a mandate by the conference delegates and organising bodies to draft a document describing the agreement position reached by those in attendance at that meeting. For the purpose of this paper, this group will be called the Concussion in Sport Group (CISG).

\section{INTRODUCTION}

This review seeks to summarise the findings of the Vienna conference and to provide a working document that will be widely applicable to sport related concussion. This document is developed for use by doctors, therapists, health professionals, coaches, and other people involved in the care of injured athletes, whether at the recreational, elite, or professional level.

During the course of the symposium, a persuasive argument was made that a comprehensive systematic approach to concussion would be of potential benefit to aid the injured athlete and direct management decisions. ${ }^{1}$ This protocol represents a work in progress, and, as with all other guidelines or proposals, it must undergo revision as new information is added to the current literature and understanding of this injury.

The concussion in sport protocol includes:

(1) Clinical history

(2) Evaluation

(3) Neuropsychological testing

(4) Imaging procedures

(5) Research methods

(6) Management and rehabilitation

(7) Prevention

(8) Education

(9) Future directions

(10) Medicolegal considerations

\section{A REVISED DEFINITION OF CONCUSSION}

Over 35 years ago, the committee on head injury nomenclature of the Cona "consensus" definition of concussion. The American Medical Association and the International Neurotraumatology Association subsequently endorsed this definition. ${ }^{3}$ This definition was recognised as having a number of limitations in accounting for the common symptoms of concussion. In addition, there was an inability to include relatively minor impact injuries that result in persistent physical and/or cognitive symptoms. Seeking to transcend these limitations, the CISG has developed the following definition of concussion.

"Concussion is defined as a complex pathophysiological process affecting the brain, induced by traumatic biomechanical forces. Several common features that incorporate clinical, pathological, and biomechanical injury constructs that may be used in defining the nature of a concussive head injury include: gress of Neurological Surgeons proposed
(1) Concussion may be caused by a direct blow to the head, face, neck, or elsewhere on the body with an "impulsive" force transmitted to the head.

(2) Concussion typically results in the rapid onset of short lived impairment of neurological function that resolves spontaneously.

(3) Concussion may result in neuropathological changes but the acute clinical symptoms largely reflect a functional disturbance rather than structural injury.

(4) Concussion results in a graded set of clinical syndromes that may or may not involve loss of consciousness. Resolution of the clinical and cognitive symptoms typically follows a sequential course.

(5) Concussion is typically associated with grossly normal structural neuroimaging studies.

\section{THE CISG CONCUSSION PROTOCOL}

\section{Clinical history}

Recognising the importance of a detailed concussion history and appreciating the fact that many athletes will not recognise all the concussions that they may have suffered in the past, a detailed concussion history is of value. The athlete currently at a high performance level in collision sport has seldom had the first concussion on presentation in the consultant's office. The history should include specific questions as to previous symptoms of a concussion, not just perceived number of past concussions. ${ }^{4}$ It is also worth noting that dependence on the recall of concussive injuries by teammates or coaches has been shown to be unreliable. ${ }^{5}$ The finding that there is increased risk of subsequent concussive injuries after a first concussion is documented, although the reasons for this remain controversial. The clinical history should also include information about all previous head, face, or neck injuries as these may have clinical relevance to the present injury. It is worth emphasising that, in the setting of faciomaxillary injuries, coexistent concussive injuries may be missed unless specifically assessed.

Specific questions about disproportionate impact and matching of symptom severity may allude to progressively increasing vulnerability to injury-that is, more pronounced persistent symptoms from smaller hits. The pathophysiological nature of this phenomenon remains unclear.

* This statement is being published simultaneously with the Clinical Journal of Sport Medicine and the Physician and Sportsmedicine. 
Table 1 Scale of postconcussion symptoms

\begin{tabular}{|c|c|c|c|c|c|c|c|}
\hline \multirow[b]{3}{*}{ Headache } & \multicolumn{7}{|c|}{ Rating } \\
\hline & \multicolumn{3}{|c|}{ None } & \multicolumn{3}{|c|}{ Moderate } & \multirow{2}{*}{$\begin{array}{l}\text { Severe } \\
6\end{array}$} \\
\hline & 0 & 1 & 2 & 3 & 4 & 5 & \\
\hline Nausea & 0 & 1 & 2 & 3 & 4 & 5 & 6 \\
\hline Vomiting & 0 & 1 & 2 & 3 & 4 & 5 & 6 \\
\hline Drowsines & 0 & 1 & 2 & 3 & 4 & 5 & 6 \\
\hline Numbness or tingling & 0 & 1 & 2 & 3 & 4 & 5 & 6 \\
\hline Dizziness & 0 & 1 & 2 & 3 & 4 & 5 & 6 \\
\hline Balance problems & 0 & 1 & 2 & 3 & 4 & 5 & 6 \\
\hline Sleeping more than usual & 0 & 1 & 2 & 3 & 4 & 5 & 6 \\
\hline Sensitivity to light & 0 & 1 & 2 & 3 & 4 & 5 & 6 \\
\hline Sensitivity to noise & 0 & 1 & 2 & 3 & 4 & 5 & 6 \\
\hline Feeling slowed down & 0 & 1 & 2 & 3 & 4 & 5 & 6 \\
\hline Feeling like "in a fog" & 0 & 1 & 2 & 3 & 4 & 5 & 6 \\
\hline Difficulty concentrating & 0 & 1 & 2 & 3 & 4 & 5 & 6 \\
\hline Difficulty remembering & 0 & 1 & 2 & 3 & 4 & 5 & 6 \\
\hline Trouble falling asleep & 0 & 1 & 2 & 3 & 4 & 5 & 6 \\
\hline More emotional than usual & 0 & 1 & 2 & 3 & 4 & 5 & 6 \\
\hline Irritability & 0 & 1 & 2 & 3 & 4 & 5 & 6 \\
\hline Sadness & 0 & 1 & 2 & 3 & 4 & 5 & 6 \\
\hline Nervousness & 0 & 1 & 2 & 3 & 4 & 5 & 6 \\
\hline Other & 0 & 1 & 2 & 3 & 4 & 5 & 6 \\
\hline
\end{tabular}

One of the issues that was speculated upon at the conference was whether concussion represents a unitary phenomenon with a linear spectrum of injury severity or whether different concussion subtypes exist. These subtypes may represent differences in clinical manifestations (confusion, memory problems, loss of consciousness), anatomical localisation (cerebral $v$ brainstem, for example), biomechanical impact (rotational $v$ linear force), genetic phenotype (ApoE4 positive $v$ ApoE4 negative), neuropathological change (structural injury $v$ no structural injury), or an as yet undefined difference. These factors may operate independently or interact with each other. It is clear that the variations in clinical outcome from the same impact force require a more sophisticated approach to the understanding of this phenomenon than is currently available. ${ }^{6}$

The traditional approach to severe traumatic brain injury using loss of consciousness as the primary measure of injury severity has acknowledged limitations in assessing the severity of concussive injury. Findings in this field describe association of loss of consciousness with specific early deficits but does not necessarily imply severity. Further work in this area may help to explain these findings. ${ }^{7}$

There is renewed interest in the role of amnesia (anterograde/retrograde) and its manifestation of injury severity. ${ }^{8}$ Published evidence suggests that the nature, burden, and duration of the clinical postconcussive symptoms may be more important than previously recognised. ${ }^{9-11}$

\section{Concussion grading scales}

The CISG recognised the strengths and weaknesses of several existing concus- sion grading scales that attempt to characterise injury severity, but no single system was endorsed. It was the recommendation of the CISG that combined measures of recovery (see below) should be used to assess injury severity (and/or prognosis) and hence individually guide decisions on return to play. dated return to play guidelines, a clinical construct is recommended using an assessment of injury recovery and graded return to play. The protocol outlined below is adapted from the Canadian Academy of Sport Medicine (CASM) guidelines. ${ }^{12}$ Sideline evaluation includes clinical evaluation of signs and symptoms, ideally using a standardised scale of postconcussion symptoms (table 1) for comparison purposes, and acute injury testing as described below under neuropsychological testing.

\section{Evaluation}

Sideline evaluation including neurological assessment and mental status testing is an essential component in the protocol. These evaluations are ideally developed in language translations for international sporting groups (an example of such a sideline evaluation developed at McGill University is available in English and French; for a copy, contact author $\mathrm{KMJ})$. In the acute assessment of concussive injury-that is, concussion diagnosis-brief neuropsychological test batteries that assess attention and memory function have been shown to be practical and effective. Such tests include the Maddock's questions ${ }^{14}$ and the Standardised Assessment of Concussion (SAC). ${ }^{15}$ It is worth noting that standard orientation questions-for example, time, place, person-have been shown to
In the absence of scientifically vali- be unreliable in the sporting situation compared with memory assessment. ${ }^{14} 16$

It is recognised, however, that abbreviated testing paradigms are designed for rapid evaluation of concussion on the sidelines and are not meant to replace comprehensive neuropsychological testing, which is sensitive enough to detect subtle deficits that may exist beyond the acute episode.

\section{Signs and symptoms of acute} concussion

If any one of the following symptoms or problems is present, a head injury should be suspected, and appropriate management instituted. A player does not need to have lost consciousness to suffer a concussion.

\section{(a) Cognitive features}

Unaware of period, opposition, score of game

Confusion

Amnesia

Loss of consciousness

Unaware of time, date, place

\section{(b) Typical symptoms}

Headache

Dizziness

Nausea

Unsteadiness/loss of balance

Feeling "dinged" or stunned or "dazed" "Having my bell rung"

Seeing stars or flashing lights

Ringing in the ears

Double vision

Other symptoms such as sleepiness, sleep disturbance, and a subjective feeling of slowness and fatigue in the setting of an impact may indicate that a concussion has occurred or has not resolved.

\section{(c) Physical signs}

Loss of consciousness/impaired conscious state

Poor coordination or balance

Concussive convulsion/impact seizure

Gait unsteadiness/loss of balance

Slow to answer questions or follow directions

Easily distracted, poor concentration

Displaying unusual or inappropriate emotions, such as laughing or crying

Nausea/vomiting

Vacant stare/glassy eyed

Slurred speech

Personality changes

Inappropriate playing behavior-for example, running in the wrong direction

Appreciably decreased playing ability 


\section{Neuropsychological assessment after concussion}

The application of neuropsychological testing in concussion has been shown to be of value and continues to contribute significant information in concussion evaluation. ${ }^{17}$ It has been shown that cognitive recovery may precede or follow resolution of clinical symptoms, suggesting that the assessment of cognitive function should be an important component in any return to play protocol.

In the consideration of injury recovery or return to play, such test strategies must assess the cognitive domains of information processing, planning, memory, and switching mental set. Numerous paradigms are in current use. Examples of these include paper and pencil tests (McGill ACE, SAC), condensed batteries (McGill ACE), comprehensive protocols administered by neuropsychologists (NHL, Australian football), and computerised test platforms-for example, IMPACT, CogSport, ANAM, Headminders. ${ }^{18}$

\section{The consensus of the CISG was that neuropsychological testing is one of the cornerstones of concussion evaluation and contributes significantly to both understanding of the injury and management of the individual.}

Overriding principles common to all neuropsychological test batteries is the need for and benefit of baseline preinjury testing and serial follow up. Recent work with computerised platforms, however, suggests that performance variability may be a key measure for diagnosis of acute concussion even in the absence of a baseline test. This strategy is currently the subject of continuing research. Inherent problems with most neuropsychological tests include the normal ranges, sensitivity and specificity of tests, and practice or learning effect, as well as the observation that players may return to baseline while still symptomatic. ${ }^{17}{ }^{19}$ In part, these may be a problem of the currently available pen and paper tests. Computerised testing using infinitely variable test paradigms may overcome these concerns. Computerised testing also has the logistical advantage that the tests may be administered by the team doctor or be web based rather than having to employ a neuropsychologist for a formal assessment. The strengths and weaknesses of such testing have been recently reviewed. ${ }^{18}$

The consensus of the CISG was that neuropsychological testing is one of the cornerstones of concussion evaluation and contributes significantly to both understanding of the injury and management of the individual. Organised sport federations have access to and should attempt to employ such testing as appropriate. To maximise the clinical utility of such neuropsychological assessment, baseline testing is recommended.

\section{Neuroimaging}

It was recognised by the CISG that conventional structural neuroimaging is usually normal in concussive injury. Given that caveat, the following suggestions are made. Brain computed tomography (or where available magnetic resonance imaging (MRI) brain scan) contributes little to concussion evaluation, but should be used whenever suspicion of a structural lesion exists. Examples of such situations may include prolonged disturbance of conscious state, focal neurological deficit, seisure activity, or persistent clinical or cognitive symptoms.

Newer structural MRI modalities, including gradient echo, perfusion, and diffusion weighted imaging, have greater sensitivity for structural abnormalities; however, the lack of published studies as well as the absence of preinjury neuroimaging data limits the usefulness of this approach in clinical studies at the present time. In addition, the predictive value of various MRI abnormalities that may be incidentally discovered is not established at the present time. Promising new functional imaging-for example, PET/SPECT/fMRI-technologies, while producing some compelling findings, are still at the early stages of development. $^{20}$

Although neuroimaging may play a part in postconcussive return to play decisions or for the assessment of moderate to severe brain injury, it is not essential for otherwise uncomplicated concussive injury.

\section{Research methods}

A number of research protocols and data evaluating concussion injury assessment, injury susceptibility, and brain function after injury were presented at the Vienna conference. All of these techniques, while offering great potential for injury assessment, must be considered experimental at this time. As much as possible, elite and professional teams are well placed to contribute to these efforts through athlete recruitment for studies showing the scientific value of such approaches.

Electrophysiological recording (ERP, EEG) has shown reproducible abnormalities in the postconcussive state in brain function. ${ }^{19}$ Similarly, balance testing has shown impairment after injury, although the mechanism for this is not established. Biochemical serum markers of brain injury (including S-100b, NSE, $\mathrm{MBP}$ ) were proposed as means of detecting cellular damage if present.

Genetic phenotyping has been shown to be of benefit in traumatic brain injury. Published studies have shown that ApoE4 is a risk factor for adverse outcome following moderate to severe brain injury. ${ }^{21}$ Similarly ApoE4 has been shown to be a risk factor for the development of chronic traumatic encephalopathy in boxers. ${ }^{22}$ The significance of ApoE4 in concussion risk or injury outcome is unclear. Other published studies have noted the association of a particular calcium subunit gene abnormality with brain swelling after minor head trauma. ${ }^{23}$

Such research is vital in contributing to the science of concussion and will potentially provide valuable information for such important issues as clinical management, return to play guidelines, and long term outcome. Therefore research should be continued and encouraged by sporting organisations.

\section{Management and rehabilitation Acute response}

When a player shows ANY symptoms or signs of a concussion:

(1) The player should not be allowed to return to play in the current game or practice.

(2) The player should not be left alone; and regular monitoring for deterioration is essential.

(3) The player should be medically evaluated after the injury.

(4) Return to play must follow a medically supervised stepwise process.

A player should never return to play while symptomatic. "When in doubt, sit them out!"

\section{Rehabilitation}

It was the consensus of the CISG that a structured and supervised concussion rehabilitation protocol is conducive to optimal injury recovery and safe and successful return to play. The rehabilitation principles were common to all identified programmes and are outlined below. Important principles state that the athlete be completely asymptomatic and have normal neurological and cognitive evaluations before the start of the rehabilitation programme. Therefore the more prolonged the symptom duration, the longer the athlete will have sat out. The athlete will then proceed stepwise with gradual incremental increases in exercise duration and intensity, and pause or backtrack with any recurrence of concussive symptoms. It is appreciated that, although each step may take a minimum of one day, depending on the duration of symptoms, proceeding through each step may take longer in individual circumstances. 
Return to play protocol Return to play after a concussion follows a stepwise process:

(1) No activity, complete rest. Once asymptomatic, proceed to level (2).

(2) Light aerobic exercise such as walking or stationary cycling.

(3) Sport specific training-for example, skating in hockey, running in soccer.

(4) Non-contact training drills.

(5) Full contact training after medical clearance.

(6) Game play.

With this stepwise progression, the athlete should continue to proceed to the next level if asymptomatic at the current level. If any symptoms occur after concussion, the patient should drop back to the previous asymptomatic level and try to progress again after 24 hours.

\section{Prevention}

As part of the clinical history, it is advised that details of the protective equipment used at the time of injury be sought, for both recent and remote injuries. The benefit of this approach allows modification and optimisation of protective behaviour and an opportunity for education. That said, there are relatively few methods by which concussive brain injury may be minimised in sport. The brain is not an organ that can be conditioned to withstand injury. Thus, extrinsic mechanisms of injury prevention must be sought.

\section{Rule changes and rule enforcement play a key role in reducing and preventing concussions.}

Helmets have been proposed as a means of protecting the head and theoretically reducing the risk of brain injury. In sports in which high speed collisions can occur or which have the potential for missile injuries-for example, baseballor for falls on to hard surfaces-for example, gridiron, ice hockey-there is published evidence that use of sport specific helmets reduces head injuries. ${ }^{3}$ For other sports such as soccer and rugby, no sport specific helmets have been shown to be of benefit in reducing rates of head injury. ${ }^{24}$ Some believe that the use of protective equipment may deleteriously alter playing behaviour so that the athlete actually increases his or her risk of brain injury. ${ }^{25}$

Although the use of correctly fitting mouthguards can reduce the rate of dental, orofacial, and mandibular injuries, the evidence that they reduce cerebral injuries is largely theoretical, and no clinical evidence for a beneficial effect in reducing concussion rates has yet been demonstrated clinically. ${ }^{26}$
Consideration of rule changes, such as no head checking in ice hockey, to reduce the head injury rate may be appropriate where a clear cut mechanism is implicated in a particular sport. Similarly, rule enforcement is a critical aspect of such approaches and referees play an important role.

Conditioning of the neck muscles may be of value in reducing impact forces transmitted to the brain. Biomechanical concepts dictate that the energy from an impacting object is dispersed over the greater mass of an athlete if the head is held rigidly. Although attractive from a theoretical standpoint, there is little scientific evidence for the effectiveness of such measures.

Rule changes and rule enforcement play a key role in reducing and preventing concussions.

\section{Education}

As the ability to treat or reduce the effects of concussive injury after the event is minimal, education of athletes, colleagues, and those working with them, as well as the general public is a mainstay of progress in this field. Athletes and their healthcare providers must be taught how to detect concussion, its clinical features, assessment techniques, and principles of safe return to play. Methods to improve education including various web based resources (for example, www.concussionsafety.com), educational videos, outreach programmes, concussion working groups, and the support and endorsement of enlightened sport groups such as FIFA, IOC, and IIHF who initiated this endeavour have enormous value and must be pursued vigorously.

The promotion of fair play and respect for opponents are ethical values that should be encouraged in all sports and sporting associations. Similarly coaches, parents, and managers play an important part in ensuring these values are implemented on the field of play.

\section{Future directions}

Efforts to evaluate long term outcome and any association with repeated concussion, molecular markers, imaging, and functional deficits must guide continuing investigation in this work. Efforts to expand knowledge of injury that may or may not be associated with particular manoeuvres inherent to the game, such as heading in soccer, must be elucidated.

A proposal was made that this concussion working group be identified and given a mandate to provide continuing leadership in the continued development and updating of guidelines and maintenance of the pursuit of a high standard of care in concussion.

\section{Medicolegal considerations}

Although agreement exists about the principal messages conveyed by this document, the authors acknowledge that the science of concussion is at the early stages and therefore management and return to play decisions remain largely in the realm of clinical judgment on an individual basis. It is the intention of the group to analyse the medicolegal aspect of concussions in sports and to offer here a summary of the state of the art and to direct future efforts.

\section{ACKNOWLEDGEMENTS}

The Vienna CIS Group thanks the other participants of the symposium for input and enthusiasm, which generated discussion of these ideas. We also thank Darlene Scheurich whose expert organisational abilities contributed to the success of this symposium.

\section{Br J Sports Med 2002;36:6-10}

\section{Authors' affiliations}

M Aubry, Chief Medical Officer, International Ice Hockey Federation

R Cantu, Chief, Neurosurgery Service and Director, Sports Medicine Service, Emerson Hospital, Concord, MA, USA. Medical Director, National Center for Catastrophic Sports Injury Research, Chapel Hill, NC, USA

J Dvorak, Chairman, FIFA Medical Research and Assessment Center (F-MARC), Wilhelm Neurologist and Director of Schulthess Clinic Zurich, Switzerland

T Graf-Baumann, FIFA Medical Research and Assessment Center (F-Marc), Tenningen,

Germany

K Johnston, Chair, Concussion in Sport Group FIFA, IIHF, IOC; Neurosurgeon and Director of Neurotrauma, McGill University Health Centre (MUHC), McGill University and McGill Sport Medicine Centre, Montreal, Canada J Kelly, Associate Professor of Clinical Neurology, Northwestern University Medical School, Chicago Neurological Institute, Chicago, IL, USA

M Lovell, Director, Sports Medicine Concussion Program, University of Pittsburgh. Co-director, National Hockey League Neuropsychology

Program, Pittsburgh, PA, USA

P McCrory, Brain Research Institute and Center for Sports Medicine Research and Education, University of Melbourne, Melbourne, Australia W Meeuwisse, University of Calgary Sport Medicine Center, Sport Injury Consultant, National Hockey League, Calgary, Alberta, Canada

P Schamasch, Director, International Olympic Committee Medical Commission, Lausanne, Switzerland

Correspondence to: Dr Johnston, Division of Neurosurgery, Montreal General Hospital, 1650 Cedar Ave, Room L7-524, Montreal, Quebec, Canada H3G 1 A4

\section{REFERENCES}

1 Johnston KM, Lassonde M, Ptito A. A contemporary neurosurgical approach to sport-related head injury: the McGill concussion protocol. J Am Coll Surg 2001;192:515-24.

2 Congress of Neurological Surgeons. Committee on Head Injury Nomenclature: glossary of head injury. Clin Neurosurg 1966;12:386-94.

3 Johnston K, McCrory P, Mohtadi N, et al. Evidence based review of sport-related concussion: clinical science. Clin J Sport Med $2001 ; 11: 150-60$

4 Delaney JS, Lacroix V, Leclerc S, et al. Concussion during the 1997 Canadian football league season. Clin J Sport Med 2000;10:9-14. 


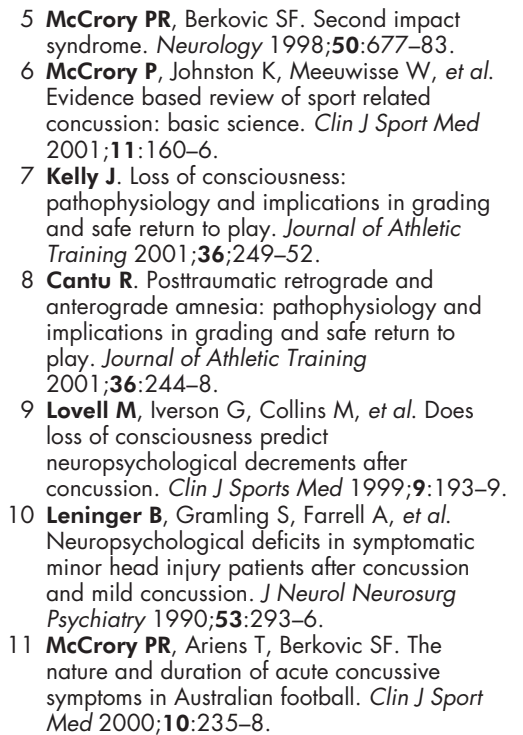

12 Committee CAoSMC CASM Guidelines for assessment and management of sport-related concussion. Clin J Sport Med 2000;10:209-11.

13 Lovell MR, Collins MW. Neuropsychological assessment of the college football player. J Head Trauma Rehabil 1998:13:9-26.

14 Maddocks DL, Dicker GD, Saling MM. The assessment of orientation following concussion in athletes. Clin J Sport Med 1995;5:32-5.

15 McCrea M, Kelly J, Randolph C, et al. Standardised assessment of concussion (SAC): on site mental status evaluation of the athlete. J Head Trauma Rehabil 1998;13:27-36.

16 McCrea M, Kelly JP, Kluge J, et al. Standardized assessment of concussion in football players. Neurology 1997;48:586-8.

17 Grindel S, Lovell M, Collins M. The assessment of sport-related concussion: the evidence behind neuropsychological testing and management. Clin J Sport Med $2001 ; 11: 134-44$

18 Collie A, Merouf $P$, Darby D. Computerised neuropsychological testing in sport. Br J Sports Med 2002.36:in press.

19 Dupuis $\mathbf{F}$, Johnston KM, Lavoie $M$, et al. Concussions in athletes produce brain dysfunction as revealed by event-related potentials. NeuroReport 2000;1 1:4087-92.
20 Johnston K, Ptito A, Chankowsky J, et al. New fronteirs in diagnostic imaging in concussive head injury. Clin J Sport Med 2001:11:166-76.

21 Teasdale G, Nicol J, Murray G. Association of Apolipoprotein E polymorphism with outcome after head injury. Lancet 1997;350:1069-71.

22 Jordan B, Relkin N, Ravdin L. Apolipoprotein E epsilon 4 associated with chronic traumatic brain injury in boxing. JAMA 1997; 278: 136-40.

23 Kors E, Terwindt G, Vermeulen F, et al. Delayed cerebral edema and fatal coma after minor head trauma: role of the CACNAIA calcium channel subunit gene and relationship with familial hemiplegic migraine. Ann Neurol 2001;49:753-60.

24 Mclntosh A, McCrory P. Impact energy attenuation performance of football headgear. Br J Sports Med 2000;34:337-42.

25 Finch C, Mclntosh A, McCrory P. What do under 15 year old schoolboy rugby union players think about protective headgear? $\mathrm{Br} J$ Sports Med 2001;35:89-95.

26 McCrory P. Do mouthguards prevent concussion? Br J Sports Med 200 1;35:81-3.

\section{New criteria for female athlete triad syndrome?}

\section{K M Khan, T Liu-Ambrose, M M Sran, M C Ashe, M G Donaldson, J D Wark}

\section{As osteoporosis is rare, should osteopenia be among the criteria for defining the female athlete triad syndrome?}

$\mathrm{T}$ he American College of Sports Medicine (ACSM) has provided a great deal of impetus to educating healthcare providers, athletes, and the general public about the potential harm of a "serious syndrome consisting of disordered eating, amenorrhoea and osteoporosis". ${ }^{1}$ We recognise and respect the importance of research and attention to this clinical problem and commend the ACSM on its contribution to date. ${ }^{2}$ To their credit, the authors of the most recent position stand acknowledged that there were no data reporting prevalence on this condition, ${ }^{3}$ and they encouraged further research. Since then, Mayo Clinic physiatrist Tamara Lauder ${ }^{4}$ has published two important papers showing a $0 \%$ prevalence of the female athlete triad (as defined by ACSM) despite 34\% of this military population being at risk of disordered eating. Therefore we reexamined the prevalence of one component of the female athlete triad, osteoporosis, in studies of athletic women with menstrual disturbance. The syndrome can be no more prevalent than any one of its diagnostic criteria alone. Thus, if osteoporosis is only present in a small proportion of the population, then it follows that the female athlete triad can only be prevalent in an equally small, or smaller, proportion of that population.

\section{DIFFERENTIATING OSTEOPOROSIS FROM OSTEOPENIA}

Because of the increasing public awareness of osteoporosis and its complications, medical practitioners must not use the term as a synonym for "low bone mass". The current standard for measuring bone mass (bone mineral density; BMD) is by dual energy $x$ ray absorptiometry, and since 1994 the term osteoporosis has had diagnostic criteria based on this technique. ${ }^{367}$ Osteoporosis is defined as BMD more than 2.5 standard deviations below the mean of young adults. The term osteopenia describes BMD scores between 1 and 2.5 standard deviations below the mean of young adults. Scrutiny of many papers examining BMD data in athletes at risk of the female athlete triad syndrome (table 1) suggests that osteopenia has a significant prevalence but that osteoporosis is relatively uncommon, even in this selected population. In the substantial reviews of Bennell et al, ${ }^{89}$ menstrual disturbance was associated with a mean $10.3 \%$ lower lumbar spine BMD, which reflects the lower limit of normal BMD and very early osteopenia ( $\mathrm{T}$ score about $-1.0)$. Not surprisingly, numerous authors reporting bone health of sportswomen have used osteopenia as the appropriate term. $^{810-13}$ Interestingly, even in the significant pathology of anorexia nervosa, the mean BMD of patients reflects osteopenia rather than osteoporosis. ${ }^{11}$ A crucial point is that significant osteopenia-that is, T-score of -2.0 -in a 20 year old may provide a worse prognosis for long term bone health than osteoporosis in a 65 year old with a T-score of -2.6 .

Osteoporosis can, and does, occur in athletes $^{14}{ }^{15}$ (table 1), but we argue that requiring this condition to be present in the female athlete triad syndrome relegates the syndrome to relative obscurity. It is unlikely that the prevalence of osteoporosis in athletes with disordered eating could be greater than the prevalence of osteoporosis in anorexia nervosa (table 2). Therefore, the female athlete triad, as currently defined, most likely has a lower prevalence than anorexia nervosa. This is borne out by the data of Lauder $e^{2}$ al $^{4}$ showing that the prevalence of anorexia nervosa was $<8 \%$ but the prevalence of the female athlete triad was $0 \%$. Anorexia nervosa has an overall age adjusted incidence per 100000 person years of 14.6 for females and 1.8 for males. ${ }^{16}$ Thus, if osteoporosis is a diagnostic criterion for the female athlete triad, the triad should have an age adjusted incidence of substantially less than $0.015 \%$ in the population at large. Note that this calculation is not based on anorexia being an essential component of the triad-it is not. These data merely recognise the fact that osteoporosis, as strictly defined, affects only a proportion 
Table 1 Prevalence of osteoporosis and osteopenia at the lumbar spine as measured by dual energy $x$ ray absorptiometry in athletic populations considered at risk of the female athlete triad

\begin{tabular}{|c|c|c|c|c|}
\hline Reference & $\begin{array}{l}\text { Population studied (age as mean } \\
\text { (SD)) }\end{array}$ & $\begin{array}{l}\text { Number of } \\
\text { subjects in } \\
\text { the at risk } \\
\text { population }\end{array}$ & $\begin{array}{l}\text { Prevalence of either osteoporosis } \\
\text { or osteopenia }\end{array}$ & $\begin{array}{l}\text { Mean T score for group (lumbar spine } \\
\text { unless stated) }\end{array}$ \\
\hline Lauder et $a l^{4}$ & Military recruits aged 27.5 (7.7) & 423 & $0 \%$ osteoporosis, $1.4 \%$ osteopenia & Not given \\
\hline Young et $a^{\beta 3}$ & $\begin{array}{l}\text { Elite ballet school students aged } 17 \\
\text { (1.2), all had menstrual disturbance }\end{array}$ & 44 & $0 \%$ osteoporosis, $22 \%$ osteopenia & $\begin{array}{l}-2.1 \text { at the lumbar spine (osteopenia), } \\
+2.1 \text { at the femoral neck (normal) }\end{array}$ \\
\hline Rutherford $^{34}$ & $\begin{array}{l}\text { Amenorrhoeic triathletes and distance } \\
\text { runners aged } 29.5(7.5)\end{array}$ & 15 & $13 \%$ osteoporosis, $40 \%$ osteopenia & -1.5 (osteopenia) \\
\hline Tomten et $a^{\beta 5}$ & $\begin{array}{l}\text { Runners with menstrual disturbance } \\
\text { aged } 27.6(5.8)\end{array}$ & 13 & Not given & $\begin{array}{l}-1.2 \text { (estimated from graph }=\text { mild } \\
\text { osteopenia) }\end{array}$ \\
\hline Drinkwater et $a^{\beta 6}$ & $\begin{array}{l}\text { Amenorrhoeic runners and rowers } \\
\text { aged } 24.9(4.7)\end{array}$ & 13 & Not given & -1.6 (osteopenia) \\
\hline Cann et $a^{\beta 7}$ & $\begin{array}{l}\text { Women with hypothalamic } \\
\text { amenorrhoea (all but one were } \\
\text { runners) aged } 27.3 \text { (6.1) }\end{array}$ & 11 & Not given & -1.3 (mild osteopenia) \\
\hline Nelson et $a^{\beta 8}$ & $\begin{array}{l}\text { Amenorrhoeic distance runners aged } \\
25.2(4.7)\end{array}$ & 11 & Not given & -0.97 (normal, borderline osteopenia) \\
\hline Warren et $a l^{12}$ & Amenorrhoeic dancers aged 19 (3.4) & 22 & Not given & -0.88 (normal) \\
\hline Pettersson et $a^{\beta 9}$ & $\begin{array}{l}\text { Amenorrhoeic distance runners aged } \\
21.8(3.0)\end{array}$ & 10 & $10 \%$ osteoporosis, $50 \%$ osteopenia & $\begin{array}{l}-1.4 \text { (estimated from graph }=\text { mild } \\
\text { osteopenia) }\end{array}$ \\
\hline Micklesfield et al ${ }^{10}$ & $\begin{array}{l}\text { Amenorrhoeic ultramarathon runners } \\
\text { aged } 35 \text { (4.3). }\end{array}$ & 10 & $\begin{array}{l}\text { Not given but probably a significant } \\
\text { number with osteoporosis }\end{array}$ & -2.1 (osteopenia) \\
\hline Myburgh et $a f^{40}$ & $\begin{array}{l}\text { Amenorrhoeic college athletes aged } \\
29.3(6.9) \text { years }\end{array}$ & 9 & Not given & -1.2 (mild osteopenia) \\
\hline
\end{tabular}

A T score between -1.0 and -2.5 represents osteopenia.

of those with the most severe form of eating disorder-anorexia. ${ }^{11}$

\section{Osteoporosis can, and} does, occur in athletes, but we argue that requiring this condition to be present in the female athlete triad syndrome relegates the syndrome to relative obscurity.

The condition of osteopenia is important and in postmenopausal women confers a doubling of the normal fracture risk and warrants attention. ${ }^{11}$ Also, an athlete with osteopenia is at greater risk of developing osteoporosis than is an athlete with normal bone mass. If either osteopenia or osteoporosis were accepted as criteria for impaired bone health, the female athlete triad syndrome would have greater prevalence and clinical relevance. Any athlete with osteopenia should optimise their lifestyle to try to maintain bone mass and increase bone strength. ${ }^{17}$ Physical activity and adequate nutrition are keystones to management of osteopenia; there is no evidence that pharmacotherapy is indicated to treat it.

\section{DID THE CHANGING DEFINITIONS OF OSTEOPOROSIS CAUSE THIS SITUATION?}

How did this arguably inappropriate use of the term osteoporosis arise? The 1993 position stand stated that "osteoporosis in this group of young female athletes refers to premature bone loss and inadequate bone formation, resulting in low bone mass, microarchitectural deterioration, increased skeletal fragility, and an increased risk of fracture" ${ }^{18}$ If the increased risk of fracture refers to "stress fracture" rather than osteoporotic fracture, this definition accurately reflects the bone health consequences associated with inadequate energy availability. This 1993 position stand preceded the World Health Organization definition of osteoporosis based on the BMD criteria as outlined above. Perhaps the 1997 position stand definition of osteoporosis was updated to reflect the new definition without there being time to consider the clinical implications inherent in the new, BMD based, definition.

Table 2 Prevalence of osteoporosis and osteopenia at the lumbar spine as measured by dual energy $x$ ray absorptiometry in patients with anorexia nervosa

\begin{tabular}{|c|c|c|c|c|}
\hline Reference & Population studied (age as mean (SD)) & $\begin{array}{l}\text { Number of } \\
\text { subjects } \\
\text { studied }\end{array}$ & $\begin{array}{l}\text { Prevalence of either } \\
\text { osteoporosis or } \\
\text { osteopenia }\end{array}$ & $\begin{array}{l}\text { Mean T score (lumbar spine unless } \\
\text { stated) }\end{array}$ \\
\hline Grinspoon et $a l^{11}$ & Women with anorexia nervosa aged 24.4 (5.7) & 130 & $\begin{array}{l}13 \% \text { osteoporosis } \\
50 \% \text { osteopenia }\end{array}$ & -1.4 (mild osteopenia) \\
\hline Young et $a^{\beta 3}$ & Anorexia nervosa patients aged $18.1(0.17)$ & 18 & $\begin{array}{l}6 \% \text { osteoporosis ( } 1 \text { subject) } \\
39 \% \text { osteopenia }\end{array}$ & -1.0 (mild osteopenia/borderline normal) \\
\hline Bachrach et al ${ }^{41}$ & Anorexia nervosa patients aged $15.9(1.5)$. & 18 & $\begin{array}{l}17 \% \text { osteoporosis* } \\
66 \% \text { had BMD }<-2 \\
56 \% \text { osteopenia }\end{array}$ & -1.5 (osteopenia) \\
\hline Seeman et $a t^{42}$ & $\begin{array}{l}\text { Patients with anorexia nervosa aged } 21 \text { years } \\
\text { (range } 12-40 \text { ) }\end{array}$ & 210 & Not given & -1.2 and -1.0 at the femoral neck \\
\hline Seeman et $a t^{43}$ & $\begin{array}{l}\text { Patients with anorexia nervosa and secondary } \\
\text { amenorrhoea aged } 24.4(8.4)\end{array}$ & 37 & Not given & -1.5 (osteopenia) \\
\hline Grinspoon et a ${ }^{22}$ & $\begin{array}{l}\text { Adolescents with anorexia nervosa and } \\
\text { secondary amenorrhoea aged } 16.0 \text { (1.7) }\end{array}$ & 19 & $\begin{array}{l}<21 \% \text { with osteoporosis } \\
50 \% \text { osteopenia } \dagger\end{array}$ & -1.0 (mild osteopenia, borderline normal) \\
\hline
\end{tabular}

A T score between -1.0 and -2.5 represents osteopenia.

*Two of these three subjects were aged 12 and arguably still gaining bone, so this may represent an overestimate of osteoporosis.

†Different data in abstract $(42 \%)$ and results sections $(50 \%)$ for AP lumbar spine by dual energy $x$ ray absorptiometry. 


\section{IS IT TIME TO REPLACE "OSTEO- POROSIS" WITH "OSTEOPENIA OR OSTEOPOROSIS" IN THE POSITION STAND?}

There have been many scientific advances since the ACSM's 1997 position stand was developed based on "a comprehensive literature survey, research studies, case reports, and the consensus of experts". Because of the authority of the College and its experts, we believe that such a document must be updated regularly, despite the enormous challenges that this entails. We believe that this process has already started. Therefore, we respectfully ask: does the ACSM want to emphasise a condition that is rare (osteoporosis) in the young active population at risk of disordered eating or would it be preferable to acknowledge the importance of a condition that has greater prevalence (osteopenia) and lends itself to lifestyle modification treatment from a multidisciplinary team that is well represented within College ranks?

\section{SUMMARY}

We believe that the widespread association of the term osteoporosis with athletic activity through the term female athlete triad may not accurately reflect the currently available evidence. We note recent data emphasising the importance of disordered eating, not exercise per se, in causing suboptimal bone mass. ${ }^{19-22} \mathrm{Dr}$ Carol Otis, one of America's greatest contributors to women's health, emphasises that "the triad is not caused by participation in sport". ${ }^{23}$ Thus, the word athlete appears to be a victim caught in the pathway from low energy availability to impaired bone health. ${ }^{19}$ This unfortunate association adds a hurdle for those committed to promoting recreational physical activity in the primary prevention of chronic disease. ${ }^{24}$

Our respectful suggestion should not, in any way, be considered a criticism of the ACSM or the authorities that have devoted their enormous scientific and educational endeavours to this important aspect of women's health. We support their commitment to preventing the complications associated with disordered eating, which, as in the case of US gymnast Christy Heinrick, include death. As the references in this leader attest, we commend and applaud the work of Anne Loucks $^{1925-32}$ and others who are authors of the ACSM position stand. We ourselves are proud to serve the ACSM in various capacities, and, together with our colleagues in the ACSM and around the world, aim to raise awareness of the threat of inadequate energy availability to bone health.

Br J Sports Med 2002;36:10-13

\section{Authors' affiliations}

K M Khan, T Liu-Ambrose, M C Ashe, M G Donaldson, University of British Columbia, Bone Health Research Group, Departments of Family Practice and Human Kinetics, University of British Columbia, Vancouver, Canada M M Sran, Osteoporosis Program, BC Women's Hospital and Health Centre, Vancouver, Canada

J D Wark, Department of Medicine, University of Melbourne, Royal Melbourne Hospital, Melbourne, Australia

Correspondence to: Dr Khan, James Mather Building, 5084 Fairview Avenue, Vancouver V6T 1Z3, Canada; kkhan@interchange.ubc.ca

\section{REFERENCES}

1 ACSM. ACSM's guidelines for exercise testing and prescription. Hagerstown, MD: Lippincott Williams and Wilkins, 2000.

2 Nattiv A, Agostini R, Drinkwater B, et al. The female athlete triad. The inter-relatedness of disordered eating, amenorrhea, and osteoporosis. Clin Sports Med 1994;13:405-18

3 Otis CL, Drinkwater $B$, Johnson $M$, et al. ACSM position stand on the female athlete triad. The female athlete triad. Med Sci Sports Exerc 1997;29:i-ix.

4 Lauder TD, Williams MV, Campbell CS, et al. The female athlete triad: prevalence in military women. Mil Med 1999;164: 630-5.

5 Donaldson MG, Khan KM, McKay HA, et al. Be careful with the term 'bone loss'. Can Med Assoc J 2001;165:269-70.

6 Kanis JA, Melton III L, Christiansen C, et al. The diagnosis of osteoporosis. J Bone Miner Res 1994;9:1137-41.

7 WHO Study Group. Assessment of fracture risk and its application to screening for postmenopausal osteoporosis. Geneva: World Health Organization, 1994.

8 Bennell KL, Malcolm SA, Wark JD, et al. Skeletal effects of menstrual disturbances in athletes. Scand J Med Sci Sports 1997;7:261-73.

9 Bennell KL. Skeletal effects of menstrual disturbance. In: Khan K, McKay H, Kannus P, et al, eds. Physical activity and bone health. Champaign, IL: Human Kinetics, 2001:201-14, 52-3.

10 Micklesfield LK, Lambert EV, Fataar AB, et al. Bone mineral density in mature premenopausal ultramarathon runners. Med Sci Sports Exerc 1995;27:688-96.

11 Grinspoon S, Thomas E, Pitts S, et al Prevalence and predictive factors for regional osteopenia in women with anorexia nervosa. Ann Intern Med 2000;133:790-4.

12 Warren MP, Brooks-Gunn J, Fox RP, et al. Lack of bone accretion and amenorrhea: evidence for a relative osteopenia in weightbearing bones. J Clin Endocrinol Metab 1991;72:847-53

13 Carmichael KA, Carmichael DH. Bone metabolism and osteopenia in eating disorders. Medicine 1995;74:254-67.

14 Dugowson CE, Drinkwater BL, Clark JM. Nontraumatic femur fracture in an oligomenorrheic athlete. Med Sci Sports Exerc 1991;23:1323-5

15 Brotman AW, Stern TA. Osteoporosis and pathologic fractures in anorexia nervosa. Am J Psychiatry 1985; 142:495-6.

16 Lucas AR, Beard CM, O'Fallon WM, et al. 50-year trends in the incidence of anorexia nervosa in Rochester, Minn.: a population-based study. Am J Psychiatry 1991;148:917-22.

17 Khan K, McKay H, Kannus P, et al. Physical activity and bone health. Champaign, IL: Human Kinetics, 2001

18 Yeager KK, Agostini R, Nattiv A, et al. The female athlete triad. Med Sci Sports Exerc 1993;25:775-7.

19 Loucks AB, Verdun M, Heath EM. Low energy availability, not stress of exercise, alters LH pulsatility in exercising women. J Appl Physiol 1998;84:37-46.

20 Hilton LK, Loucks AB. Low energy availability, not exercise stress, suppresses the diurnal rhythm of leptin in healthy young women. Am J Physiol Endocrinol Metab 2000;278:E43-9.

21 Soyka LA, Grinspoon S, Levitsky LL, et al. The effects of anorexia nervosa on bone metabolism in female adolescents. J Clin Endocrinol Metab 1999;84:4489-96.

22 Grinspoon S, Herzog D, Klibanski A. Mechanisms and treatment options for bone loss in anorexia nervosa. Psychopharmacol Bull 1997;33:399-404

23 O'Dwyer J. The female triad. Sport Health 2001;19:31-4.

24 Booth FW, Gordon SE, Carlson CJ, et al. Waging war on modern chronic diseases: primary prevention through exercise biology. J Appl Physiol 2000;88:774-87.

25 Loucks AB, Horvath SM. Exercise-induced stress responses of amenorrheic and eumenorrheic runners. J Clin Endocrinol Metab 1984;59:1109-20.

26 Loucks AB, Horvath SM, Freedson PS. Menstrual status and validation of body fat prediction in athletes. Hum Biol 1984; 56:383-92.

27 Loucks AB. Osteoporosis begins in childhood. In: Brown EW, Branta CF, eds. Competitive sports for children and youth. Champaign, IL: Human Kinetics, 1988:213-33

28 Loucks AB, Mortola JF, Girton L, et al. Alterations in the hypothalamic-pituitary-ovarian and the hypothalamic-pituitary-adrenal axes in athletic women. J Clin Endocrinol Metab 1989;68:402-11.

29 Loucks AB, Laughlin GA, Mortola JF, et al. Hypothalamic-pituitary-thyroidal function in eumenorrheic and amenorrheic athletes. J Clin Endocrinol Metab 1992;75:514-18.

30 Loucks AB, Vaitukaitis J, Cameron JL, et al. The reproductive system and exercise in women. Med Sci Sports Exerc 1992;24:S288-93

31 Loucks AB, Heath EM. Dietary restriction reduces luteinizing hormone $(\mathrm{LH})$ pulse frequency during waking hours and increases LH pulse amplitude during sleep in young menstruating women. J Clin Endocrinol Metab 1994;78:910-15.

32 Loucks AB, Verdun M. Slow restoration of LH pulsatility by refeeding in energetically disrupted women. Am J Physiol 1998;275:R1218-26.

33 Young N, Formica C, Szmukler G, et al. Bone density at weight-bearing and non weight-bearing sites in ballet dancers: the effects of exercise, hypogonadism and body weight. J Clin Endocrinol Metab 1994;78:449-54.

34 Rutherford OM. Spine and total body bone mineral density in amenorrheic endurance athletes. J App Physiol 1993;74:2904-8.

35 Tomten SE, Falch JA, Birkeland KI, et al. Bone mineral density and menstrual irregularities. A comparative study on cortical and trabecular bone structures in runners with alleged normal eating behavior. Int I Sports Med 1998;19:92-7.

36 Drinkwater BL, Nilson $\mathrm{K}$, Chesnut $\mathrm{CH}$, et al. Bone mineral content of amenorrheic and eumenorrheic athletes. N Engl J Med 1984;311:277-81

37 Cann CE, Martin MC, Genant HK, et al. Decreased spinal mineral content in amenorrheic women. JAMA 1984;251:626-9.

38 Nelson ME, Fisher EC, Catsos PD, et al. Diet and bone status in amenorrheic runners. $\mathrm{Am} J$ Clin Nutr 1986;43:910-16.

39 Pettersson U, Stalnacke B, Ahlenius G, et al. Low bone mass density at multiple skeletal sites, including the appendicular skeleton in amenorrheic runners. Calcif Tissue Int 1999;64: 1 17-25. 
40 Myburgh $\mathrm{KH}$, Bachrach LK, Lewis B, et al. Low bone mineral density in axial and appendicular sites in amenorrheic athletes. Med Sci Sports Exerc 1993;25: 1197-202.

41 Bachrach L, Guido D, Katzman D, et al. Decreased bone density in adolescent girls with anorexia nervosa. Paediatrics 1990;86:440-7.

42 Seeman B, Karlsson MK, Duan Y. On exposure to anorexia nervosa, the temporal variation in axial and appendicular skeletal development predisposes to site-specific deficits in bone size and density: a cross-sectional study. J Bone Miner Res 2000:15:2259-65.

43 Seeman E, Szmukler GI, Formica C, et al. Osteoporosis in anorexia nervosa: the influence of peak bone density, bone loss, oral contraceptive use, and exercise. J Bone Miner Res 1992:7: 1467-74.

\section{COMMENTARY}

Dr Khan and colleagues have provided an excellent review and scientific analysis of the available evidence on the osteoporosis component of the female athlete triad and have brought to light some important concepts regarding the triad definitions, prevalence, and clinical relevance in the athlete population. Over the last decade since the initial Triad Consensus Conference in 1992, there has been much research on disordered eating and inadequate energy availability, amenorrhea, and bone health concerns in the female athlete, which has greatly enhanced our understanding of the pathogenesis of the various components of the triad, and has helped us to better prevent and treat athletes with these medical concerns. Because of the advances in our understanding and management of the triad, an update on the ACSM Position Stand is warranted and is underway.

The components of the triad as initially described were meant to alert athletes and their health care team, as well as parents, coaches, and the public to the potential dangers of these medical disorders, their interrelationships and comorbidities, and to serve as an assessment of risk rather than as strict diagnostic criteria for a medical syndrome. It is important to emphasise that each of the components of the triad lie on a spectrum. While it is acknowledged that osteopenia in the young female athlete is more common than osteoporosis, it is important to realise the potential that exists for the development of osteoporosis if the other interrelated components of the triad are not recognised and adequately treated. Furthermore, there is much research that is needed assessing the prevalence of osteopenia and osteoporosis in the female athlete population.

The original intent of the term osteoporosis as a component of the triad was to represent the end point on a spectrum of bone health that could be the poten- tial result of disordered eating and/or amenorrhea. Dr Khan and colleagues are correct in that the original description of osteoporosis as a component of the triad was indeed prior to the World Health Organization (WHO) definition of osteoporosis based on bone mineral density criteria. With this new definition, fewer young athletes will fit this criteria for osteoporosis, but the future potential for osteoporosis still exists and is a significant concern. It is also important to recognise that the WHO criteria was developed to serve as guidelines for management of osteoporosis in postmenopausal women, and no specific criteria has been developed and uniformly accepted for diagnosis and management of osteoporosis in premenopausal women, including the young female athlete. Whether the actual definition of the triad needs to be changed to better represent the available data on the prevalence of osteoporosis in the female athlete population, or a clarification and emphasis on the triad spectrum of disorders and comorbidities, is a topic for further discussion amongst our colleagues in ACSM.

A Nattiv
UCLA Department of Family Medicine,
Division of Sports Medicine and Department
of Orthopaedic Surgery; Director, UCLA
Osteoporosis Center, Los Angeles, California
USA; anattive@mednet.ucla.edu

may also have an influence. ${ }^{1}$ Our understanding of the effect that sports training has on the growing child is limited because of the difficulty in distinguishing the independent effects of training from those of normal growth. ${ }^{2}$ Only when a child is repeatedly measured from childhood through to adolescence can independent effects be identified. To date, there are limited numbers of such longitudinal studies, and hence most of our knowledge has been gained from cross sectional studies. The cross sectional nature of such studies obviously has made inferences that training delays puberty or reduces adult stature problematic.

cally mature state. Maturation differ from growth in that, although various biological systems mature at different rates, all individuals reach the same end point, becoming fully mature. Maturation therefore has two components, timing and tempo. Development refers to the acquisition of behavioral competence and is culture specific. Growth, maturation, and development occur simultaneously and interact. Growth and maturation are characterised by individual variation and, although under genetic and neuroendocrine control, environmental factors, including sport,

\section{BODY SIZE}

On average, young female athletes from most sports have statures that equal or exceed the median for the normal population. Female basketball players, volleyball players, tennis players, rowers, and swimmers have been to shown to have mean statures above the 50th centile of the reference populations from 10 years onwards. ${ }^{3}$ However, gymnasts consistently present mean values below the 50th centile, with a secular trend for decreased stature: today's elite female gymnasts are, on average, shorter than whole, and of its parts, maturat refers to progress towards the biologi- 
the gymnasts of 20 years ago. ${ }^{4}$ Figure skaters also have shorter statures. Ballet dancers tend to have shorter statures during childhood and early adolescence, but catch up with non-dancers in late adolescence. $^{3}$

\section{On average, young female athletes from most sports have statures that equal or exceed the median for the normal population.}

In general, female athletes tend to have body masses that equal or exceed the reference medians. Gymnasts, figure skaters, and ballet dancers consistently have lighter body mass. However, gymnasts and figure skaters have appropriate body mass for their height, whereas ballet dancers and distance runners have low body mass for their height. Although female athletes from a number of sports tend to be heavier than reference populations, they also, in general, have lower percentage body fat.

\section{PHYSIQUE OF YOUNG ATHLETES}

Successful early adolescent and adolescent athletes (about 12-18 years of age) tend to have, on average, somatotypes similar to adult athletes in their respective sports. ${ }^{5}$ Compared with adult female athletes, young female athletes tend to be less endomorphic, less mesomorphic, and more ectomorphic. The latter component reflects the role of growth in the transition from late adolescence into young adulthood. Physique is a significant contributor to success in many sports, and may be of particular importance in aesthetic sports such as gymnastics, figure skating, and diving, where performance scores may be influenced by how the judges perceive the athlete's physique. $^{6}$

\section{MATURATION OF YOUNG ATHLETES}

Maturity differences among young female athletes are most apparent during the transition from childhood to adolescence, and particularly during the adolescent growth spurt. During childhood, the skeletal ages of gymnasts are average or on time for chronological age. As they enter adolescence, most are classified as average and late maturing, with few early maturing girls. In later adolescence, most gymnasts are classified as late maturing. ${ }^{3}$ Gymnasts and ballet dancers tend to attain menarche later than the normal population and girls in other sports. ${ }^{7}$ Early and average maturing girls are systematically represented less among gymnasts as girls pass from childhood through adolescence, probably reflecting the selection criteria of the sport, and perhaps the performance advantage of later maturing girls in gymnastics activities. Ballet dancers and distance runners show a similar maturity gradient in adolescence. In contrast, young female swimmers tend to have skeletal ages that are average or advanced in childhood and adolescence. ${ }^{3}$

\section{STATURE AND REGULAR TRAINING}

The smaller size of elite gymnasts is evident long before any systematic training starts $^{8}$ and is in part familial. In our own studies we have found that gymnasts have parents who are shorter than average. ${ }^{9}$ There is also a size difference between those who persist in the sport and those who drop out. ${ }^{10}$ Female athletes in volleyball, diving, distance running, and basketball show rates of growth in height that, on average, closely approximate rates observed in non-athletic children, ${ }^{3}$ which are well within the range of normally expected variation among youth. ${ }^{11}$ Most recent studies have found no evidence to suggest training causes changes in anthropometric variables. ${ }^{12-15}$ Available data also indicate no effect of sport training on the age at peak height velocity or the growth rate of height during the adolescent spurt. ${ }^{3}$ Data are insufficient to warrant that intensive training may delay the timing of the growth spurt and stunt the growth spurt in female gymnasts. Many confounding factors are not considered, especially the rigorous selection criteria for gymnastics, marginal diets, short parents, and so on. Female gymnasts, as a group, show the growth and maturation characteristics of short, normal, slow maturing children with short parents. Although we believe that training does not compromise adult stature, others suggest an opposite view. A short term longitudinal study in which the adult stature of gymnasts and swimmers were predicted concluded that gymnasts were failing to obtain full familial height. ${ }^{16}$ However, decreasing predicted adult height during puberty is a characteristic of slow or late maturation, confirmed by the late onset of menarche in these subjects. ${ }^{16}$ Other studies of gymnasts, over longer time periods, have also observed lags in adolescent growth but then report subsequent catch up growth. $^{210}$ Lindholm's group ${ }^{17}$ found that six of 21 Swedish gymnasts studied over a five year period ended up 3.5-7.5 $\mathrm{cm}$ shorter than their predicted adult stature. Final height was predicted from parental heights. Although this protocol gives a target adult height, one would expect $95 \%$ of daughters to fall within a $9 \mathrm{~cm}$ range of this value. Thus, the final heights of these Swedish gymnasts ${ }^{17}$ are, in fact, well within the range of variation expected with the stature prediction method used.

In contrast with height, body mass can be influenced by regular training for sport, resulting in changes in body composition. Reduced skinfold levels have been observed in growing female athletes and are dependent on continued, regular activity or training, or continued energy restriction. This situation often occurs in sports such as gymnastics, ballet, figure skating, and diving. However, it is difficult to separate specific effects of training on fat mass from expected changes that occur with normal growth and sexual maturation during adolescence.

\section{SEXUAL MATURATION}

The limited longitudinal data for girls active in sport compared with nonathletic girls indicate no effect of training on the timing and progress of secondary sexual characteristics (development of breast and pubic hair). ${ }^{18}$ The interval between ages at peak height velocity and menarche (1.2-1.5 years) for girls active in sport and non-active girls also does not differ, and is similar to that of non-athletic girls. ${ }^{12}$ Most discussions of the potential influence of training on sexual maturation have focused on the later mean age at menarche, often observed in female athletes. ${ }^{2}$ Typically, training for sport was indicated as the factor responsible for this finding, with the inference that training "delayed" menarcheal onset. Unfortunately, most studies of athletes do not consider other confounding factors known to influence menarche. ${ }^{7}$ Thus, given the many factors known to influence menarche, sport training per se has yet to be proven beyond reasonable doubt to be the causative factor for later menarche in female athletes.

\section{CONCLUSIONS}

Concerns have centred on the suggestion that intensive training causes growth retardation and pubertal delay in female athletes, specifically gymnasts. Interestingly, male gymnasts also have consistently short statures and late maturation, but these trends are not attributed to intensive training. ${ }^{39}$ From our review of the literature, training does not appear to affect growth and maturation. It is more likely that young athletes select themselves, or are selected by coaches and sport systems, into their specific sports. Therefore, in general, the differences observed in stature between athletes and non-athletes are mainly the result of nature rather than nurture. With regard to pubertal development, the evidence suggests that the tempo is slowed down in some sports, but it has not yet been possible to identify whether this is an 
effect of nature or nurture. To clearly show that intensive training is a factor, future studies must be longitudinal, and be able to partition constitutional factors and the other components of the sport environment of female athletes before causality can be established.

\section{Br J Sports Med 2002;36:13-15}

\section{Authors' affiliations}

A D G Baxter-Jones, College of Kinesiology, University of Saskatchewan, 105 Gymnasium

Place, Saskatoon SK, S7N 5C2, Canada

N Maffulli, Department of Trauma and

Orthopaedic Surgery, Keele University School of

Medicine, North Staffordshire Hospital,

Thornburrow Drive, Hartshill, Stoke on Trent,

Staffordshire ST4 7QB, UK

Correspondence to: Professor Maffulli;

n.maffulli@keele.ac.uk

Accepted 7 November 2001

\section{REFERENCES}

1 Malina RM, Bouchard C. Growth, maturation and physical activity. Champaign, IL: Human Kinetics, 1991.
2 Baxter-Jones ADG, Helms PJ. Effects of training at a young age: a review of the training of young athletes (TOYA) study. Pediatric Exercise Science 1996;8:310-27.

3 Malina RM. Physical growth and biological maturation of young athletes. Exerc Sport Sci Rev 1994;22:389-434.

4 Beunen GP, Malina RM, Thomis M. Human growth in context. London: Smith-Gordon, 1999:281-9

5 Carter JEL. Young athletes. Champaign, IL: Human Kinetics, 1988:153-65.

6 Claessens AL, Lefevre J, Beunen G, et al. The contribution of anthropometric characteristics to performance scores in elite female gymnasts. J Sports Med Phys Fitness 1999;39:355-60.

7 Malina RM. Menarche in athletes: a synthesis and hypothesis. Ann Hum Biol 1983;10:1-24.

8 Peltenburg AL, Erich WB, Zonderland ML, et al. A retrospective growth study of female gymnasts and girl swimmers. Int J Sports Med 1984:5:262-7.

9 Baxter-Jones ADG, Helms P, Maffulli N, et al. Growth and development of male gymnasts, swimmers, soccer and tennis players: A longitudinal study. Ann Hum Biol 1995;22:381-94.

10 Tonz O, Stronski SM, Gmeiner CY. Growth and puberty in 7-to-16-year-old female gymnasts: a prospective study. Schweiz Med Wochenschr 1990;120:10-20

11 Fogelholm M, Rankinen T, Isokaanta M, et al. Growth, dietary intake, and trace element status in pubescent athletes and schoolchildren. Med Sci Sports Exerc 2000;32:738-46.

12 Geithner CA, Woynarowska B, Malina RM. The adolescent spurt and sexual maturation in girls active and not active in sport. Ann Hum Biol 1998;25:415-23.

13 Damsgaard R, Bencke J, Matthiesen G, et al Body proportions, body composition and pubertal development of children in competitive sports. Scand J Med Sci Sports $2001 ; 11: 54-60$.

14 Damsgaard R, Bencke J, Matthiesen G, et al. Is prepubertal growth adversely affected by sport? Med Sci Sports Exerc 2000 32:1698-703

15 Bass S, Bradney M, Pearce G, et al. Short stature and delayed puberty in gymnasts: influence of selection bias on leg length and the duration of training on trunk length. $J$ Pediatr 2000;136:149-55.

16 Theintz GE, Howald H, Weiss U, et al. Evidence for a reduction of growth potential in adolescent female gymnasts. J Pediatr 1993; 122:306-13.

17 Lindholm C, Hagenfeldt K, Ringertz BM. Pubertal development in elite juvenile gymnasts. Effects of physical training. Acta Obstet Gynecol Scand 1994;73:269-73.

18 Malina RM, Woynarowska B, Bielicki T, et al. Prospective and retrospective longitudinal studies of the growth, maturation, and fitness of Polish youth active in sport. Int J Sports Med 1997;18(suppl 3):s179-85.

\section{Banning pregnant netballers - is this the answer?}

\section{S White}

\section{A forum on a ban of pregnant netballers considered that the ban was discriminatory and that pregnant women should have the right to make decisions about competing in sporting activities}

A recent move by Netball Australia to ban all pregnant netballers at all levels from participating in their sport has been met with a mixture of outrage and sympathy. Those who advocate a woman's right to make decisions about her own pregnancy, including sports participation, have been vocal in their disagreement with this ban. Sporting administrators in fear of litigation and some sporting competitors concerned about playing against a pregnant opponent have welcomed the ban.

The introduction of the ban had an immediate effect, with a national level netballer announcing her pregnancy (first trimester) and applying to the Human Rights and Equal Opportunity Commission for a lifting of the ban on the basis of discrimination. The case is pending.

Such a controversial situation prompted the Australian Sports Commission to hold a national forum with a range of experts and interested parties invited to contribute. Firstly, the available medical evidence was discussed. Associate Professor Caroline Finch, Chair of the National SportSafe Committee and a leading epidemiologist in the area of sports injury, reported that there is not a single case of an adverse outcome in pregnancy related to sports participation in the world literature. Admittedly there are no specific studies on pregnancy and contact sports, but numerous studies have looked at aerobic activities and fetal outcome.

A number of papers now concur that women who take moderate exercise (less than four times a week) in fact have larger babies than non-exercisers or more extreme exercisers. ${ }^{1}$ None of these studies recorded any problems in terms of labour, delivery, or Apgar scores in any of the groups. There are now even a few studies of cognitive behaviour in newborns and 1 year old and 5 year old chil- dren all showing that those whose mothers exercised during pregnancy functioned as well as, or better than, those whose mothers did not.

\section{Current available evidence suggests that sport and exercise, if anything, has a beneficial effect on the fetus/child.}

In terms of contact in sport, the only large body of literature that considers fetal injury in relation to contact is in motor vehicle accidents and domestic violence, neither of which could be considered comparable to a game of netball. To further attempt to quantify a possible risk from sporting contact, Finch used data from two large epidemiological studies on the incidence of types of sporting injuries. In both studies, less than $2 \%$ of all injuries, in a range of sports, involved the chest or abdomen and in both studies all contacts were considered minor.

Finch conceded that there is room for more research in this area, but the current available evidence suggests that sport and exercise, if anything, has a beneficial effect on the fetus/child.

Professor Wendy Brown discussed public health issues, in particular female participation rates in sport. Professor Brown is the principal investigator with the Australian Longitudinal Study of Women's Health, involving 40000 participants. Part of the study focused on sports participation and showed that the 
biggest fall in participation rates in women is during their 20s and 30 s (child bearing years) when there are a number of practical barriers to regular exercise. Couple this with the fact that physical inactivity is one of the largest contributors to ill health, ${ }^{3}$ more so in women, then there is an overwhelming argument to encourage women to exercise during this time rather than send the wrong message by banning participation in netball (the single largest participation sport for women in Australia).

Dr Michael Sedgley, obstetrician and past chairman of the medicolegal committee of the Royal Australian and New Zealand College Of Obstetricians and Gynecologists, argued that there is no evidence to suggest that exercise during pregnancy is in anyway harmful to the fetus. He also cited research showing that exercise during pregnancy can decrease the incidence of nausea and depression and increase feelings of wellbeing in the mother. Unfortunately there is no evidence that active women have shorter or easier labours, but it is possible that they may recover more quickly in the post partum period. He advocated the right of the woman to make a choice about sports participation during pregnancy, in conjunction with her medical practitioner.

\section{Exercise during pregnancy can decrease the incidence of nausea and depression and increase feelings of wellbeing in the mother.}

A legal session involved discussion on the current Australian legislation with regard to anti-discrimination, occupational health and safety, and negligence law. Banning a person from participating in an activity because of their sex, religion, or pregnant state is against the provisions of the Antidiscrimination Act. To do so, a group must either apply for an exemption (which Netball Australia did not do) or show exceptional circumstances (the test case awaits).

In terms of the risks of negligence for sporting organisations, including its administrators, umpires, and opposing players, it has never been tested. The legal expert present stated that "causation" must be shown, and he felt that there was insufficient evidence in the current literature to support this. This point of view was disputed by some who were concerned that in a trial in which a jury may decide the matter, such an emotive case as (potential) injury to a child may affect the judgment.

A representative of the insurance industry acknowledged that one of the biggest issues facing sporting organisations in Australia is the rising cost and inaccessibility of public liability insurance, without which an organisation cannot operate. He felt that the current wording of the general policies would cover injuries to a pregnant woman and her fetus but that it had never been tested. If a case was to occur, this may significantly increase the premiumsrequired to cover future risk, making such cover beyond the reach of most sporting organisations and putting their existence in doubt.

Finally ethicists discussed the issues involving the ban, as well as confidentiality issues in relation to team medical officials in the case of a pregnant athlete involved in a sport that bans participation.

The resultant informal consensus of the forum was that the ban was discriminatory, that women should have the right to make decisions about com- peting in sporting activities (in conjunction with their medical practitioners), and that it is mandatory to better educate players, officials, and medical practitioners about the current state of knowledge on exercise during pregnancy. Litigation for negligence was considered unlikely from the current evidence in the literature.

Meanwhile Netball Australia continues its ban. This ban has generated much discussion and hopefully inspired researchers and the government to investigate and fund relevant research in this area.

The outcome of the case before the anti-discrimination board will certainly affect future policy, but it is hoped that sensible discussion of the issues, education of all parties involved, and the results of future research will contribute more to the development of participation guidelines than the fear of litigation.

Br J Sports Med 2002;36:15-16

\section{Author's affiliation}

S White, Olympic Park Sports Medicine Centre, Swan Street, Melbourne 3000, Australia

Correspondence to: Dr White; susanwhite@optusnet.com.au

\section{REFERENCES}

1 Campbell MK, Mottola MF. Recreational exercise and occupation activity during pregnancy and birthweight: a case control study. Am J Obstet Gynecol

$2001 ; 184: 403-8$.

2 Clapp JF 3rd, Lopez B, Harcar-Sevcik. Neonatal behavioral profile of the offspring of women who continue to exercise regularly throughout pregnancy. Am J Obstet Gynecol 1999;180:91-4.

3 Mathers C, Vos T, Stevenson C. The burden of disease and injury in Australia. Canberra: Australian Institute of Health and Welfare, 1999: cat no. PHE-17. athletes at specific venues in the competition, and, as a result, the information is published in a medical journal and finally reported in the lay press? Is any of this information confidential? Can any of the listed parties object to the release of a report on the basis of their "ownership" of part of the information?

One of the fundamental ethical principles of medicine is that the doctorpatient relationship is privileged and confidential. In theory, a doctor treating a professional athlete should not pass on information on that athlete's injury history without the expressed consent of the player. In practice, professional team doctors do this all the time, and players rarely object. If Joe Bloggs, the amateur, is playing football and dislocates his patient have over this stored piece of information. The issue becomes more complicated when a third party such as an insurance company is involved. What about when more than ten parties are involved? How about when a professional sporting competition and a sponsor, on the advice of a research panel, pay a consultant to collect information from salaried team doctors and an insurance 
shoulder, he can assume the right that his treating doctor will not pass on information about the injury to third parties not involved in the treatment. The situation is totally different if Joe Bloggs is a professional athlete. If he is being paid money to play football, then all of the parties involved in paying him the money (especially the viewing audience) want to know that he has dislocated his shoulder. They also want to know details, such as whether he will need surgery and how long it will be before he can play again.

\section{Professional athletes are celebrities working in a segment of the

Professional athletes are celebrities working in a segment of the entertainment industry. Unfortunately, when they suffer injuries, this is part of the entertainment. The occurrence of injuries to public figures is seen to be public information, and hence in this sense no one "owns" the information. Unlike movies, which are rated unsuitable for children on the basis of sexual or violent scenes, sporting events are open to all viewers. Publicly no sporting administrator will ever condone violence or injuries in sport, yet a quick survey of spectator sports shows a high correlation between popularity and potential for injury. No one has ever requested a copy of a video of a Formula One Grand Prix with the crash scenes edited out because they "don't like to see drivers getting hurt". Anyone tragic enough to be watching a recorded video of a motor race is probably doing it for the opposite reason-to fast forward through the "boring bits" of the race where all the drivers are staying on the road.

There are occasions in which athletes and their entourage will deliberately try to hide the details of injuries for a secondary gain. A classic example of this would be a rugby player who decides to soldier on carrying a broken rib who doesn't want his opponents to target him for extra tackling. On other occasions, athletes like to exaggerate minor injuries to cover up for a loss of form or failure to achieve selection in the team. In the vast majority of occasions, the media will be told the truth about an athlete's injury. There is a good reason for this: journalists are very good at finding out the truth about injuries. They are almost as good as bookmakers, whose profitability depends almost entirely on being the first to find out when star players are going to be missing through injury. Professional athletes of any significance will have their medical histories quickly uncovered by these two groups of allies.

\section{Publicly no sports administrator will ever condone violence or injuries in sport, yet a quick survey of spectator sports shows a high correlation between popularity and potential for injury.}

How accurate, extensive, and accessible are media reports on the injuries of professional athletes at the present time? In most cases the answers are very, very, and very. I was recently involved in a study designed to show how much detail there is available about injuries to professional athletes on the world wide web, specifically looking at the National Basketball Association (NBA). ${ }^{1}$ There are at least 13 web sites that specialise in NBA injury reports. Over two recent seasons in the NBA, every time a player missed a game, a reason was posted on the web and, in the case of injury, a body area cited. In $82 \%$ of cases, the diagnosis was more specific including a body part and injury type, even in some cases where the diagnosis may have been sensitive or career threatening. ${ }^{1}$ The diagnoses given on these web sites are generally likely to be accurate, as their collective profile shows a great similarity to the official injury profile of the NBA, which has also recently been published. ${ }^{2}$

One can argue about the accuracy of media and web reports about injuries in professional athletes, yet their proliferation makes it hard to mount a serious argument to say that confidentiality should be a barrier to performing analytical research on them. Unfortunately this argument is often made by both well meaning people who have no idea about professional sport and the legal profession. Fears about privacy do stand in the way of good research that would have the potential to benefit everyone. The most extensive injury database in professional sport is of injuries in the National Football League (NFL), which contains over 20 years of data. ${ }^{3}$ Over the same time period, NFL doctors have met at a draft combine on an annual basis to conduct preparticipation medicals on players who wished to enter the NFL. If the data from the combine and the injury survey were combined and published, the sports medicine community could be given an extensive prospective appraisal of the value of preparticipation medicals in predicting future injury risk. Apparently this has been suggested on many occasions but has never eventuated because there are too many parties with an interest in these data and no agreement can be reached about the constraints of such a study.

I have had plenty of experience of dealing with the multiple parties involved in the injury surveillance system of the Australian Football League (AFL). We have been able to conduct this research in a background of excellent cooperation from the AFL medical officers, the AFL administration, and the AFL Players Association. The prevailing attitude has been that no single stakeholder "owns" the injury data, but each must be consulted in the process of conducting a study or analysis using these data. There is a danger that, with so many parties having a right of veto, important studies may not see the light of day. We must keep our eye on the ball to prevent this from happening. To date, I consider that it is fortunate that we have never submitted the AFL Injury Surveillance System to a university ethics committee. It is quite likely that, if an ethics committee ever crossed the path of the AFL injury surveillance system, it would demand it be halted until every player in the competition had given written permission for his injury data to be analysed. Fortunately people working within the AFL industry, who appreciate that a side effect of the enormous pay packet afforded to a professional football player is that his privacy is almost non-existent, have not made this ridiculous and destructive suggestion.

\section{It is quite likely that, if an ethics committee ever crossed the path of the AFL injury surveillance system, it would demand it be halted until every player in the competition had given written permission for his injury data to be analysed.}

To date there has been a small amount of information from the AFL injury surveillance system that has been censored by consensus. The Australian media has often made us think that we should not have bothered with our modesty. An example is that we do not publish a team by team ranking of injury incidence in our reports, because of the fear that the media will sensationalise this information and unfairly taint the teams with the greatest rates of injury. Because we do not publish such a list, the media compile their own lists of which teams have suffered the most injuries, and of course use them to create sensational headlines and unfairly taint the unfortunate teams who have suffered the most injuries. This of course happens 
elsewhere. The NFL injury surveillance system has led to published relative injury rates between artificial turf and natural grass. ${ }^{3}$ Yet the American media is so hungry for information that at the end of the 1999 NFL season, the LA Times published its own study, based on media reports, comparing injury rates between teams playing on grass and artificial turf. ${ }^{4}$

The databases of injuries in professional sport, and for that matter amateur sport, are extremely valuable resources. The future of sports medicine publication is that hopefully there will be more papers published with exposures in the millions of hours, ${ }^{5}$ rather than the case series of a dozen or so patients from someone's private practice that have been the staples of sports medicine journals in the past. If we can start to get some more serious numbers in our studies, then we will reach much more important conclusions and, in the end, be taken more seriously by the rest of the medical profession. The issues of confidentiality and privacy are significant. Individuals should not have to fear what happens to their medical history, but there is a greater loss to the public by not undertaking sports medicine research because of disputes over data ownership.

Br J Sports Med 2002;36: 16-18

\section{Author's affiliation}

J Orchard, South Sydney Sports Medicine

111 Anzac Parade, Kensington, NSW 2033, Australia

Correspondence to: Dr Orchard; johnorchard@msn.com.au

\section{REFERENCES}

1 Orchard J, Hayes J. Using the World Wide Web to conduct epidemiological research: an example using the National Basketball Association. International Sport Medicine Journal $2001 ; 2$. http://www.esportmed.com/ ismi/content/viewarticle.cfm?aid= 101 \&view=abs

2 Starkey, C. Injuries and illnesses in the National Basketball Association: a 10-year perspective. Journal of Athletic Training 2000;35:161-7.

3 Powell JW, Schootman M. A multivariate risk analysis of selected playing surfaces in the National Football League: 1980 to 1989. An epidemiological study of knee injuries. Am J Sports Med 1992;20:686-94.

4 Mitchell H. NFL injury report. LA Times 2000 Jan 25; sect D:8.

5 de Loes $M$. Epidemiology of sports injuries in the Swiss organization "Youth and Sports" 1987-1989. Injuries, exposure and risks of main diagnoses. Int J Sports Med $1995 ; 16: 134-8$.

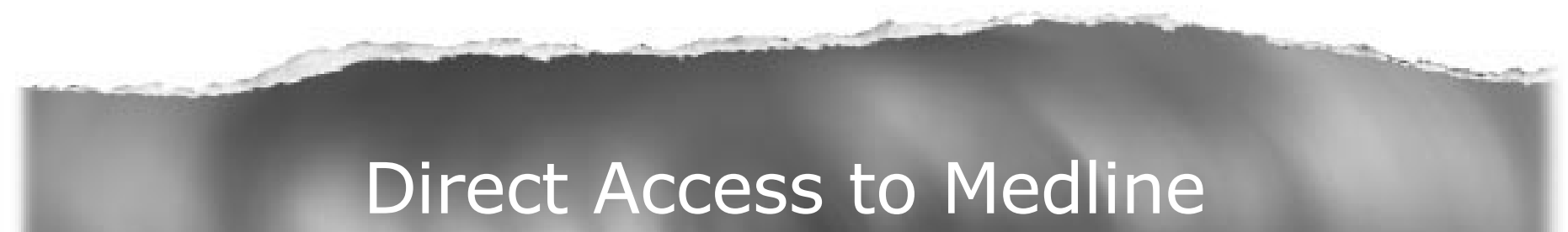

Medline

Link to Medline from the homepage and get straight into the National Library of Medicine's premier bibliographic database. Medline allows you to search across 9 million records of bibliographic citations and author abstracts from approximately 3,900 current biomedical journals.

\section{www.bjsportmed.com}

